enemies? Ss were told to "read the two relationships given on a page and understand them, then estimate the probability of the third relationship ... Assume that within a given set, all persons are acquainted and have some relationship." The scale was anchored by the words "impossible" (O\% probable) and "certain" (100\% probable).

\section{RESULTS}

Mean strain and probability ratings for the 16 structures are shown in Fig. 1. The correlation between these two sets of means is -.87 .

If the formulation offered by Henley, Horsfall, \& De Soto provides an adequate description of goodness of figure, and if ratings are an appropriate index of that goodness, mean ratings for "good" and "bad" structures should be significantly different. The structures formed of asymmetric and mixed relations were classified (as "good" or "bad") in accordance with the Henley, Horsfall, \& De Soto formulation; those formed of symmetric relations only were identified as balanced ("good") or unbalanced ("bad") according to balance theory (Cartwright \& Harary, 1956). Under this sy stem, Structures 2,4,7,11, and 13 are "bad." However, this classification results in no significant differences for either strain or probability ratings (Table 1).

Closer examination of ratings for these figures reveals that those with one or three negative lines are generally rated as relatively high in strain and low in probability. The structures were reclassified, this time the "bad figure" structures being identified as those with an odd number of negative lines, or a completely asymmetric power cycle (Structures 2, 4, 7, 8, 10, 12, 15, 16). The means under this classification are shown in Table 2. These differences are statistically significant by the $t$ test: for strain, $t=96.90, \quad \mathrm{df}=14 ;$ for probability, $t=21.80, \quad d f=14$. In both cases, the probability (one-tailed) of such a large difference is less than .0005 . Individual Ss' means for good vs bad structures were compared by the sign test. For the strain ratings, 39 of the 46 comparisons were in the expected direction $(z=4.57, p<.00003)$; for the probability ratings, all 37 comparisons were in the expected direction.

\section{DISCUSSION}

Some interesting inferences may be drawn from the high correlation between strain and probability ratings. First, there is

Table 1

Mean Strain and Probability Ratings of Structures Divided into Good and Bad Figure (Henley, Horstall, \& De Soto Classification).

\begin{tabular}{lll} 
& Good & Bad \\
\hline Strain & 4.25 & 4.67 \\
Probability & 4.55 & 4.50 \\
\hline
\end{tabular}

Table 2

Mean Strain and Probability Ratings of Structures Reclassified (see text).

\begin{tabular}{lcc}
\hline & Good & Bad \\
\hline Strain & 3.04 & 5.73 \\
Probability & 5.56 & 3.51 \\
\hline
\end{tabular}

some generality over types of asymmetric relations: "influences" and "is boss of" are essentially interchangeable in this context. Second, the strain and probability rating dimensions seem interchangeable to some degree as experimental devices for measuring goodness of figure. Third, the correlation suggests that this sort of rating task yields reliable results.

Significant differences in ratings of "good" and "bad" figures were obtained only when the structures were divided according to the second scheme, that is, when a structure with one or three negative lines, or an asymmetric power cycle, was considered "bad." Students of balance theory will recognize a correspondnece between these findings and those of balance theorists, for whom an odd number of negative lines (in elemental structures) is considered unbalancing (Cartwright \& Harary, 1956; Heider, 1958).

Obviously, the results of this experiment are not consistent with the results from the learning experiments cited by Henley, Horsfall, \& De Soto. The explanation might well lie in task differences, i.e., learning vs rating, and may be artifactual. On the other hand, there are implications for real-life situations. In cognizing social structures, people might be able to discern and recall well interpersonal relationships in structures which they would find unpleasant or which are unlikely to occur.

\section{REFERENCES}

CARTWRIGHT, D., \& HARARY, F. Structural balance: A generalization of Heider's theory. Psychological Review, 1956, 63, 277-292.

De SOTO, C. B. Learning a social structure. Joumal of Abnormal \& Social Psychology. $1960,60,417-421$.

De SOTO, C. B., \& ALBRECHT, F. Conceptual good figures. In R. P. Abelson, E. Aronson, W. J. McGuire, T. M. Newcomb, M. J. Rosenberg, and P. H. Tannenbaum (Eds.), Theories of cognitive consistency: A sourcebook. Skokie, 11.: Rand McNally, 1968a. Chap. 45.

De SOTO, C. B., \& ALBRECHT, F. Cognition and social orderings. In R.P. Abelson, E. Aronson, W. J. McGuire, T. M. Newcomb, M. J. Rosenberg, and P. H. Tannenbaum ( $\mathrm{Eds}$ ), Theories of cognitive consistency: $A$ sourcebook. Skokie, III.: Rand McNally, 1968b. Chap. 49.

De SOTO, C. B., \& KUETHE, J. L. Subjective probabilities of interpersonal relationships. Journal of Abnormal \& Social Psychology, 1959, 59, 290-294.

HEIDER, F. Attitudes and cognitive organization. Journal of Psychology, 1946, 21, 107-112.

HEIDER, F. The psychology of interpersonal relations New York: Wiley, 1958.

HE NLEY, N. M., HORSF AL L, R. B., \& De SOTO, C. B. Goodness of figure and social structure. Psychological Review, in press.

JORDAN, N. Behavioral forces that are a function of attitudes and of cognitive organization. Human Relations, 1953, 6, 273-287.

LEWIT, D. W. The learning of mixed power/liking relationships in small social structures. Paper presented at the meeting of the Eastern Psychological Association, New York, April 1963.

MANDLER, G., \& COWAN, P. Leaming of simple structures. Journal of Experimental Psychology, 1962, 64, 177-183.

\title{
Transfer of response from compound conditioned stimuli'
}

W'LLLAM W. GRINGS, Lniversity of
Southern Califormia, Los Angeles, Calif.
90007

Forty Ss were given discrimination conditioning of the GSR with one CS la pair of colored dots) accompanied by a shock, and a second CS (also a pair of colored dots) not accompanied by shock. An acquisition series was followed by a transfer test series including the original compound stimuli, the individual components, and new compounds formed by different pairing of the components. Discrimination conditioning was established but differential responding did not transfer to the components. Maximum response was obrained to new combinations (pairs) of the original components.

Recent investigations of compound stimulus conditioning of the GSR from this 
laboratory have been concerned with transfer of response from component stimuli to simple compounds composed of pairs of the components (Grings \& O'Donnell, 1956; Grings, Uno, \& Fiebiger, 1965; Grings \& Kimmel, 1959) and the interaction between responses to components and compounds (Grings \& Shmelev, 1959). Most recently the compound stimulus transfer paradigm has been used to explore counterconditioning by antagonistic response tendencies (Grings \& Uno, 1968). The present study evaluates questions regarding transfer from compounds to components and from original compounds to new compounds assembled from the components.

When the GSR is conditioned to a simple stimulus compound, like a pair of lights, and the responses to the components are later tested separately, it might be assumed that the response elicited by the components would be less in magnitude than the response to the compound, but that the response would be determined by training on the compound. That is, transfer from compound to component would be expected but the amount of transfer should be less to the component than to the original learned stimulus. Such a prediction would be made under limiting conditions, one of the most important of which would be that the compound not possess strong configural properties which might imbed or hide the components during training on the compound. A related prediction based on the assumption of a simple summative transfer between compound stimuli and their components would be that new arrangements of the components (i.e., new compounds) would elicit responses with a magnitude determined by a summation of the response tendencies of the components.

The experiment to be described established discrimination conditioning to two compound stimuli (pairs of colored lights), then, in a postconditioning test series, evaluated response magnitude to the component stimuli and to new arrangements of components into pairs.

\section{METHOD}

Forty Ss ( 28 men and 12 women) were given an adaptation series of 16 presentations of the to-be-conditioned stimuli alone. (Half received paired stimuli; half received single stimuli.) An acquisition series followed. Stimulus combinations consisted of pairs of colored dots with colors and color combinations rotated systematically among Ss. For any given $S$ during the acquisition series, two stimulus combinations were used, one followed by shock and the other not. Each combination was presented 16 times with order varied and a test trial was interspersed after each had been presented 8 times. Immediately after the last acquisition trial two test series were presented, each of which consisted of all possible pairs and single stimuli in randomly ordered blocks.

The GSR was measured as a dc resistance change from the palm to the back of S's nonpreferred hand by means of a Darrow. type bridge. The output of the bridge was led to a dc amplifier and recorded on an Esterline-Angus 0-1 mA ink-writing meter. The UCS was a condenser discharge shock delivered to the volar surface of S's arm and with intensity set by $S$. The conditioned stimuli consisted of colored dots projected on a ground glass screen 18 in. in front of the S. Time relations were controlled electronically by Hunter timers with the CS preceding the UCS by $.5 \mathrm{sec}$ and remaining on $.5 \mathrm{sec}$ after the onset of the UCS. The intertrial interval was rotated among 30,40 , and $50 \mathrm{sec}$.

\section{RESULTS}

Responses beginning within 5 sec after CS onset on test trials were transformed to the unit square root of change in conductance. This measure was averaged for the two interspersed trials during acquisition and for the post acquisition test series for all stimulus classes.

Table 1 presents the summary of results obtained during the first series of test trials after the acquisition series. The test series formed an extinction series in the sense that no UCSs were presented throughout. Compound stimuli from acquisition are labelled as originally reinforced $(++)$, and nonreinforced $(--)$. For evaluation of responses to single stimuli the GSRs to the two components from the reinforced compounds have been combined and labelled plus ( + ). Similarly, responses to the two components from the nonreinforced pairs have been combined and labelled minus $(-)$. The lumping of data was done after a comparison showed that within the plus and minus categories no differences were obtained. It will be noted that there was no appreciable transfer of differential response from compounds to components. The "new compound" represents the combination of components which forms an arrangement different from that used in acquisition. The pairs are made up of one component from the previously reinforced

\section{Table 1}

Average Magnitude of GSRs to Various Classes of Stimuli during First Postacquisition Test Series. $N=40$. Unit is Square Root of Conductance Change in Micromhos

\begin{tabular}{ll}
\hline Stimulus Class & Response \\
\hline Compounds & \\
$\quad$ Reinforced & $(++) 1.54$ \\
$\quad$ Nonreinforced & $(-) 1.17$ \\
$\quad$ New combination & $(+-) 1.66$ \\
Single Stimuli & \\
$\quad$ From reinforced pair & $(+) 1.24$ \\
From nonreinforced pair & $(-) 1.25$ \\
\hline
\end{tabular}

pair and one component from the previously nonreinforced pair.

Statistical comparisons showed that the response to the reinforced compound exceeded that to the nonreinforced compound $(t=2.02 ; p=.05)$. The responses to "new" compounds were higher than responses to any other stimulus class. This difference was significant $(t=2.26 ; p=.05)$ when "new" and nonreinforced compounds were compared, but was not significant when "new" and reinforced compounds were compared. Results from the second test series were consistent with those from the first, but the magnitudes of differences were smaller due to the general effects of extinction.

\section{DISCUSSION}

The above results suggest several conclusions about transfer in this situation. First, there is the typical transfer of differential responding from an acquisition series to an extinction series where the learned stimuli are pairs of colored dots. Secondly, there is no evidence that the effects of reinforcement of the compound are transferred to the components during the extinction-test series. Finally, there is strong evidence of transfer from acquisition to extinction associated with change of the arrangement of the stimuli in pairs different from those in acquisition. An increase in magnitude to new combinations occurs. The mechanism producing this result is not fully clear in the present situation, for the response could reflect orienting behavior, resulting from changes in stimulus conditions, or it could be due to some form of interaction (e.g., conflict) of response tendencies transferred from original acquisition. It is most likely that the increased response is a result of orienting behavior arising from stimulus change and the fact that the new combinations had not been presented previously to the Ss.

\section{REFERENCES}

GRINGS, W. W., \& O'DONNE LL, D. E. Magnitude of response to compound discriminated stimuli. Journal of Experimental Psychology, 1956,52, 345-359.

GRINGS, W. W., \& SHMELEV, V.C. Changes in GSR to a single stimulus as a result of training on a compound stimulus. Journal of Experimental Psychology, 1959, 58, 129-133.

GRINGS, W. W., \& KIMMEL, H. B. Compound stimulus transfer from different sense modalities. Psychological Reports, 1959, 5, 253-260.

GRINGS, W. W., \& UNO, T. Counterconditioning:

Feas and relaxation. Psychophysiology, 1968 , 4, 479-485.

GRINGS, W. W., UNO, T., \& FIEBIGER, J. Component to compound stimulus transfer. Psychonomic Science, 1965, 3, 63-64.

$$
\text { NOTE }
$$

1. This research was initiated under Grant G-925 from the National Science Foundation and completed under Grant MH 03916 from the National Institute of Mental Health. The author is grateful for the assistance of Dale O'Donnell in collecting the data. 